(C) 2021, The Authors. Published by Elsevier Inc. and Fass Inc. on behalf of the American Dairy Science Association ${ }^{\circledR}$. This is an open access article under the CC BY-NC-ND license (http://creativecommons.org/licenses/by-nc-nd/4.0/).

\title{
Evaluation of bull fertility in Italian Brown Swiss dairy cattle using cow field data
}

\author{
Hendyel A. Pacheco, ${ }^{1} \odot$ Mara Battagin, ${ }^{2} \odot$ Attilio Rossoni, ${ }^{2} \odot$ Alessio Cecchinato, ${ }^{3} \odot$ \\ and Francisco Peñagaricano ${ }^{1 *}$ (1) \\ ${ }^{1}$ Department of Animal and Dairy Sciences, University of Wisconsin, Madison 53706 \\ ${ }^{2}$ Italian Brown Breeders Association, Bussolengo, Verona 37012, Italy \\ ${ }^{3}$ Department of Agronomy, Food, Natural Resources, Animals and Environment, University of Padova, Legnaro, Padua 35020, Italy
}

\begin{abstract}
Dairy bull fertility is traditionally evaluated using semen production and quality traits; however, these attributes explain only part of the differences observed in fertility among bulls. Alternatively, bull fertility can be directly evaluated using cow field data. The main objective of this study was to investigate bull fertility in the Italian Brown Swiss dairy cattle population using confirmed pregnancy records. The data set included a total of 397,926 breeding records from 1,228 bulls and 129,858 lactating cows between first and fifth lactation from 2000 to 2019. We first evaluated cow pregnancy success, including factors related to the bull under evaluation, such as bull age, bull inbreeding, and AI organization, and factors associated with the cow that receives the dose of semen, including herd-year-season, cow age, parity, and milk yield. We then estimated sire conception rate using only factors related to the bull. Model predictive ability was evaluated using 10-fold cross-validation with 10 replicates. Interestingly, our analyses revealed that there is a substantial variation in conception rate among Brown Swiss bulls, with more than $20 \%$ conception rate difference between highfertility and low-fertility bulls. We also showed that the prediction of bull fertility is feasible as our cross-validation analyses achieved predictive correlations equal to 0.30 for sire conception rate. Improving reproduction performance is one of the major challenges of the dairy industry worldwide, and for this, it is essential to have accurate predictions of service sire fertility. This study represents the foundation for the development of novel tools that will allow dairy producers, breeders, and artificial insemination companies to make enhanced management and selection decisions on Brown Swiss male fertility.
\end{abstract}

Received February 19, 2021.

Accepted June 10, 2021.

*Corresponding author: fpenagarican@wisc.edu
Key words: pregnancy records, service sire fertility, sire conception rate

\section{INTRODUCTION}

Fertility is a key trait to ensure profitable and sustainable dairy farming. Causes of poor fertility in dairy cows have been well studied and efforts have been made to improve female reproductive traits, such as the incorporation of cow fertility traits into breeding programs (Walsh et al., 2011; García-Ruiz et al., 2016). Nevertheless, the reproductive performance of dairy herds remains suboptimal, which leads to significant economic losses (Inchaisri et al., 2010; Cole et al., 2016). As an example, the US Brown Swiss breed averages 2.4 breedings per conception, $63 \mathrm{~d}$ from first to last breeding, $27 \%$ conception rate, and $427 \mathrm{~d}$ of calving interval (Norman et al., 2018). Establishing a successful pregnancy in dairy cattle is a complex process and there is strong evidence that not only female fertility, but also male fertility, plays an important role. However, the genetic improvement of bull fertility has been largely ignored. Interestingly, recent studies have shown that paternal factors directly contribute to pregnancy success, including the fertilization process and even early embryo development (DeJarnette et al., 2004; Kropp et al., 2014; Immler, 2018; Ortega et al., 2018).

Bull fertility is traditionally estimated in the laboratory based on semen analysis. This approach uses conventional laboratory methods, which measure semen production traits, such as volume and sperm concentration, and semen quality traits, such as motility and percentage of abnormal sperm (DeJarnette et al., 2004). Interestingly, significant fertility differences exist among bulls producing spermatozoa with normal motility, morphology, and count (Soderquist et al., 1991). Since bull fertility is influenced by a wide range of factors, it is unlikely that a single sperm characteristic test can accurately predict fertility (Kastelic and Thundathil, 2008). Indeed, laboratory semen analyses should be considered as indicator traits of bull fertility, 
whereas the true fertility of a bull must be estimated using field records.

Sire fertility can be directly evaluated using cow field records, based on whether inseminated cows returned to service within a defined time period or confirmed pregnancy records (Berry et al., 2011). Due to the complexity of fertility, various factors such as herd, cow age, cow parity, DIM, and month of insemination, cause variations in bull fertility using field records (Stahlhammar et al., 1994). In this context, previous studies have developed statistical models to estimate bull fertility accounting for nuisance variables related to the cow that receives the semen dose. For instance, the US dairy industry has access to a phenotypic evaluation of service sire fertility called sire conception rate (SCR; Kuhn and Hutchison, 2008; Kuhn et al., 2008). This bull fertility evaluation is based on a large, nationwide database of confirmed pregnancy records, available for Holstein, Jersey, Brown Swiss, Ayrshire, Guernsey, and Milking Shorthorn sires. In Australia, a national dairy bull fertility evaluation, semen fertility value (SFV), is provided to dairy farmers by DataGene (Melbourne, Australia). This evaluation uses nonreturn to service records to estimate the conception rate of a bull (Carrick et al., 2000; Rezende et al., 2020). Both SCR and SFV are phenotypic evaluations defined as the expected difference in conception rate of a given bull compared with the mean of all the bulls evaluated. Unfortunately, most national evaluations for fertility are limited to female fertility traits, and evaluations for male fertility are commonly undertaken by individual breeding organizations and usually not made public (Berry et al., 2011).

The Brown Swiss breed has a great significance for the dairy industry, the breed is raised worldwide due to its adaptability to different climates. Europe has the largest Brown Swiss population, which is led by Switzerland, Germany, and Italy. The breed is also popular in the United States, where it is the third most prevalent breed of dairy cattle when considering the number of registered elite cows (CDCB, 2020). The European Brown Swiss Federation estimates that there are over 6 million Brown Swiss animals worldwide (European Brown Swiss Federation, 2015). Given the worldwide relevance of the Brown Swiss cattle, the main objective of this study was to investigate bull fertility in the Italian Brown Swiss dairy cattle population using cow field records. First, we evaluated alternative statistical models for cow pregnancy success, including factors related to both the bull under evaluation and the cow that receives the dose of semen. We then estimated SCR using only factors related to the bull. We assessed model predictive ability for both cow pregnancy success and SCR using cross-validation techniques.

\section{MATERIALS AND METHODS}

\section{Description of Data and Editing Procedure}

The Italian Brown Swiss Breeders Association (Verona, Italy) provided a total of $1,144,453$ breeding records. The data editing consisted of keeping only lactating cows from first to fifth lactation, removing both nulliparous cows (heifers) and multiparous cows that were beyond their fifth lactation. Days in milk at breeding was required to be between 30 and $450 \mathrm{~d}$, and a minimum of $4,536 \mathrm{~kg}$ for total milk yield (MY). The herd-year-season (HYS) consisted of 4 different seasons ( 1 = March, April, and May; 2 = June, July, and August; 3 = September, October, and November; $4=$ December, January, and February), combined with cow herd and year of the breeding, and only HYS with 5 or more records were kept. A maximum of 7 services were allowed for each cow within lactation. Only bulls with 50 or more breedings that were utilized in at least 5 HYS were used in the analyses. Artificial insemination company was combined with year to account for any changes that could occur in different years within the same AI company. Both age of the cow and inbreeding of the bull were provided in the original data set, whereas age of the bull and inbreeding of the mating (potential embryo) were calculated using a pedigree file with more than 5 generations. Both cow age and bull age were considered in months. Only records with complete information were maintained in the final data set. After edits, a total of 397,926 breeding records from 1,228 bulls and 129,858 lactating cows from 2000 to 2019 were retained for subsequent analyses. Table 1 shows the number of records left after applying the editing procedure for each variable.

\section{Statistical Model: Cow Pregnancy Success}

Previous research has indicated that linear models are as effective as threshold models for evaluating cow fertility in dairy cattle (Abdollahi-Arpanahi et al., 2013). Thus, cow pregnancy success was investigated using the following final linear model:

$$
\begin{aligned}
y & =\text { Lactation }+ \text { ServiceNumber }+\beta_{1} \times \mathrm{DIM}+\beta_{2} \times \mathrm{DIM}^{2} \\
& +\beta_{3} \times \mathrm{MY}+\beta_{4} \times \mathrm{MY}^{2}+\beta_{5} \times \mathrm{Age}_{\text {bull }}+\beta_{6} \times \mathrm{Age}_{\text {bull }}^{2} \\
& +\beta_{7} \times \mathrm{Age}_{\text {cow }}+\beta_{8} \times \mathrm{Age}_{\text {cow }}^{2}+\beta_{9} \times \text { Inbreeding }_{\text {bull }} \\
& +\beta_{10} \times \text { Inbreeding }_{\text {bull }}^{2}+\beta_{11} \times \text { Inbreeding }_{\text {mating }}+\beta_{12} \\
& \times \text { Inbreeding }_{\text {mating }}^{2}+\text { AIcompany_year }+\mathrm{HYS}+\text { Bull } \\
& +\mathrm{PE}_{\text {cow }}+\mathrm{A}_{\text {cow }}+e,
\end{aligned}
$$


Table 1. Description of the data editing process

\begin{tabular}{llr}
\hline Variable & Criteria & Records after editing \\
\hline Total records & & $1,144,453$ \\
Lactation & First to fifth & 794,389 \\
Cow's age & 20 (first lactation) to 115 mo (fifth lactation) & 781,685 \\
DIM & Between 30 and 450 d & 767,835 \\
Total milk yield & $\geq 4,536 \mathrm{~kg}$ & 728,012 \\
Bull's age & 13 to 168 mo & 718,659 \\
AI company and year & No missing information & 697,737 \\
Service number & Maximum 7 services & 687,051 \\
Bull breedings & At least 50 breedings in at least 5 herd-year- & 397,926 \\
& seasons & \\
\hline
\end{tabular}

where $y$ was the binary outcome of the insemination $(0=$ failure, $1=$ pregnancy $)$. Categorical fixed effects included lactation number (parity order) and service number. The variables DIM at breeding, total MY, bull age $\left(\right.$ Age $\left._{\text {bull }}\right)$, cow age $\left(\mathrm{Age}_{\text {cow }}\right)$, inbreeding of the bull (Inbreeding $\left.{ }_{\text {bull }}\right)$, and inbreeding of the potential embryo (Inbreeding mating $)$ were fitted as both linear and quadratic covariates ( $\beta_{1}$ to $\beta_{12}$ are regression coefficients). Random effects included AIcompany_year as the effect of the AI organization of the bull for the year of mating, and the effect of HYS of the cow at breeding; Bull was the service sire effect; the terms $\mathrm{PE}_{\text {cow }}$ and $\mathrm{A}_{\text {cow }}$ were the random permanent environmental and additive genetic effects of the cow, respectively; and $e$ was the random error. Random effects were assumed to follow a multivariate normal distribution:

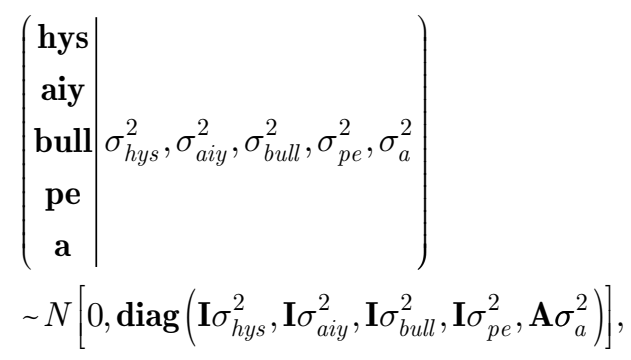

where $\mathbf{I}$ was an identity matrix, $\mathbf{A}$ was the additive relationship matrix, and $\sigma_{i}^{2}$ was the scalar variance for the corresponding effect. All these analyses were performed using AIREML and BLUPF90 (Misztal et al., 2018) programs for mixed model computations in animal breeding.

\section{Statistical Model: Sire Conception Rate}

Sire conception rate was estimated following Kuhn et al. (2008) using different factors closely related to the fertility of the bull:

$$
\mathrm{SCR}=100 \times\left(\begin{array}{l}
\hat{\beta}_{5} \times \text { Age }_{\text {bull }}+\hat{\beta}_{6} \times \mathrm{Age}_{\text {bull }}^{2}+\hat{\beta}_{9} \\
\times \text { Inbreeding }_{\text {bull }}+\hat{\beta}_{10} \times \text { Inbreeding }_{\text {bull }}^{2} \\
+\overline{\text { AIcompany_year }}+\widehat{\text { Bull }}
\end{array}\right)
$$

The solutions for the linear and quadratic effects for age and inbreeding of the bull, namely $\hat{\beta}_{5}, \hat{\beta}_{6}, \hat{\beta}_{9}$, and $\hat{\beta}_{10}$, and the solutions for the random effects $\widehat{\text { AIcompany_year }}$ and $\widehat{\text { Bull }}$ were all obtained from the model used to evaluate cow pregnancy success. The proportion of the total variation in SCR due to additive genetic effects was estimated using a classical animal model with SCR as response variable and the kinship matrix constructed using pedigree information. Finally, for those bulls also evaluated in United States, the similarity between male fertility evaluations (i.e., similarity between SCR values calculated in Italy and United States) was assessed using the Spearman's rank correlation coefficient.

\section{Phenotypic Prediction: Cow Pregnancy Success}

The predictive ability of the cow pregnancy success model was evaluated by a 10 -fold cross-validation. The entire data set $(397,926$ records) was divided at random into 10 subsets. Nine out of the 10 subsets were combined to create the training set (train), whereas the remaining subset was used as the testing set (test). In the testing set, the outcome of the insemination (0 or 1 ) was set as missing value. Then, pregnancy success in the testing set was predicted using the following model: $\hat{\mathbf{y}}_{\text {test }}=\mathbf{X}_{\text {test }} \hat{\mathbf{b}}_{\text {train }}+\mathbf{Z}_{\text {test }} \hat{\mathbf{u}}_{\text {train }}$, where $\mathbf{X}_{\text {test }}$ and $\mathbf{Z}_{\text {test }}$ are design matrices, and $\hat{\mathbf{b}}_{\text {train }}$ and $\hat{\mathbf{u}}_{\text {train }}$ are vectors of fixed and random effects, respectively. Each of the 10 subsets was used as a testing population one time. The entire 10-fold cross-validation process was repeated 10 times; therefore, the analysis resulted in 100 estimations. 
Table 2. Description of different cow-related variables per lactation number

\begin{tabular}{lrrrrr}
\hline & \multicolumn{5}{c}{ Lactation } \\
\cline { 2 - 6 } Item & First & Second & Third & Fourth & Fifth \\
\hline Total inseminations & 154,735 & 112,171 & 77,905 & 48,176 & 27,525 \\
Pregnancy at first AI, \% mean & 25 & 25 & 24 & 23 & 22 \\
Service number, mean & 1.79 & 1.80 & 1.83 & 1.86 & 1.88 \\
DIM, mean & 127 & 126 & 129 & 132 & 134 \\
Herd-year-season & 36,786 & 33,587 & 28,717 & 21,818 & 14,668 \\
Cow age, mo & & & & & \\
Mean & 34 & 48 & 62 & 75 & 88 \\
Minimum & 20 & 32 & 44 & 100 & 115 \\
Maximum & 60 & 72 & 84 & & 8,734 \\
Milk yield, kg & & & & & \\
$\quad$ Mean & 7,315 & 8,289 & 8,736 & 8,818 & 8,736 \\
Minimum & 4,536 & 4,537 & 4,536 & 4,536 & 17,506 \\
Maximum & 15,509 & 17,642 & 18,702 & 17,737 & \\
\hline
\end{tabular}

Model predictive performance was assessed using the Pearson product moment correlation between observed and predicted values in the testing population. Additionally, the mean-squared error of prediction (MSEP) was calculated as a measure of prediction bias and variability, using the following formula:

$$
\operatorname{MSEP}=n^{-1} \sum_{f=1}^{10} \sum\left(y-\hat{y}_{\text {test }}\right)^{2},
$$

where $n$ is the number of records in each fold $(f)$, and $y$ and $\hat{y}$ are the observed and predicted pregnancy outcomes, respectively.

\section{Phenotypic Prediction: Sire Conception Rate}

The predictive ability of the SCR model was also evaluated by a 10 -fold cross-validation with 10 repetitions. As before, the entire data set (397,926 records) was divided at random into 10 subsets. The training set was used to estimate all the unknowns from the cow pregnancy success model. Then, these estimates were used to predict SCR values in the testing set. The predictive performance of the SCR model was assessed using the Pearson product moment correlation between predicted SCR values and bull's conception rate $(\mathbf{C R})$ in the testing population. Bull's CR was calculated as the number of inseminations that resulted in pregnancy divided by the total number of inseminations in the testing set.

\section{RESULTS}

\section{Description of Data and Editing Procedure}

After data editing, 397,926 insemination records from 129,858 cows between first and fifth lactation remained for analyses. Table 2 provides a description of different variables of interest per lactation number. A total of 1,228 Brown Swiss bulls met all applied criteria, which were on average $66 \mathrm{mo}$ old and their age ranged from 13 to 168 mo. These bulls had an average of 324 breedings, a median number of breedings equal to 136 , with a minimum of 50 and maximum of 8,110 breedings per bull. These bulls were from 20 different AI companies, with records from 2000 to 2019. After combining the AI company and year of the insemination into one variable, there were 239 different classes.

\section{Statistical Model: Cow Pregnancy Success}

Fixed effects Lactation and ServiceNumber, as well as linear and quadratic covariates DIM, MY, and $\mathrm{Age}_{\text {bull }}$, as well as $\mathrm{Age}_{\text {cow }}$ as quadratic covariate, were all statistically significant. On the other hand, linear covariate Age $_{\text {cow }}$ and both linear and quadratic covariates Inbreeding ${ }_{\text {bull }}$ and Inbreeding mating $_{\text {were not statisti- }}$ cally significant. Table 3 shows the proportion of total variance explained by the different random effects. Cow additive genetic effect explained the largest variance $(3.9 \%)$, the random effect herd-year-season explained $3.4 \%$, whereas the bull effect explained roughly $1 \%$. The random effect AIcompany_year explained only $0.2 \%$, the smallest proportion of the total variance.

\section{Statistical Model: Sire Conception Rate}

Sire conception rate was defined as deviation from the mean, which was set as 0 , so each 1-point difference reflects a $1 \%$ improvement in CR. Figure 1 shows the distribution of SCR values for the population of bulls evaluated. The SCR records follow a classical long-tail, bell-shaped distribution. Most of the bulls show similar fertility, although there is a wide range in 
Table 3. Estimates of (co)variance components for cow pregnancy success

\begin{tabular}{lcc}
\hline Random effect $^{1}$ & Variance & \% total variance \\
\hline Bull & 0.003 & 1.0 \\
HYS & 0.008 & 3.4 \\
AIcompany_year & 0.001 & 0.2 \\
PE $_{\text {cow }}$ & 0.001 & 0.5 \\
$\mathrm{~A}_{\text {cow }}$ & 0.010 & 3.9 \\
$e$ & 0.223 & 91.0 \\
\hline
\end{tabular}

${ }^{1} \mathrm{HYS}=$ herd-year-season; AIcompany_year = AI company within year; $\mathrm{PE}_{\mathrm{cow}}=$ permanent environmental effect of the cow; $\mathrm{A}_{\mathrm{cow}}=\mathrm{ad}-$ ditive genetic effect of the cow; $e=$ random error.

SCR values with more than $20 \%$ CR difference between high-fertility and low-fertility bulls. Interestingly, $20 \%$ of the total variation in SCR was explained by additive genetic effects. Finally, a total of 44 of the 1,228 Brown Swiss bulls evaluated had also male fertility records in United States, and the correlation between Italian and American SCR values was $+0.35(P \leq 0.01)$.

\section{Phenotypic Prediction: Cow Pregnancy Success}

Predictive performance of 4 different models for cow pregnancy success was evaluated using 10-fold crossvalidation repeated 10 times, so each analysis resulted in 100 estimates of predictive correlation and MSEP (Figure 2). The first model included all the cow and bull-associated variables, except MY, AIcompany_

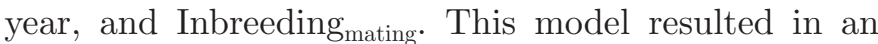
average predictive correlation of $17.6 \%$ and an average MSEP of 0.241. The other 3 models included sequentially MY as linear and quadratic covariate (model 2), AIcompany_year as a random effect (model 3), and finally Inbreeding ${ }_{\text {mating }}$ (model 4). All 3 of these models achieved an average predictive correlation of $21.9 \%$ and an average MSEP of 0.236 .

\section{Phenotypic Prediction: Sire Conception Rate}

Model predictive ability for SCR was also evaluated using a 10-fold cross-validation with 10 repetitions,

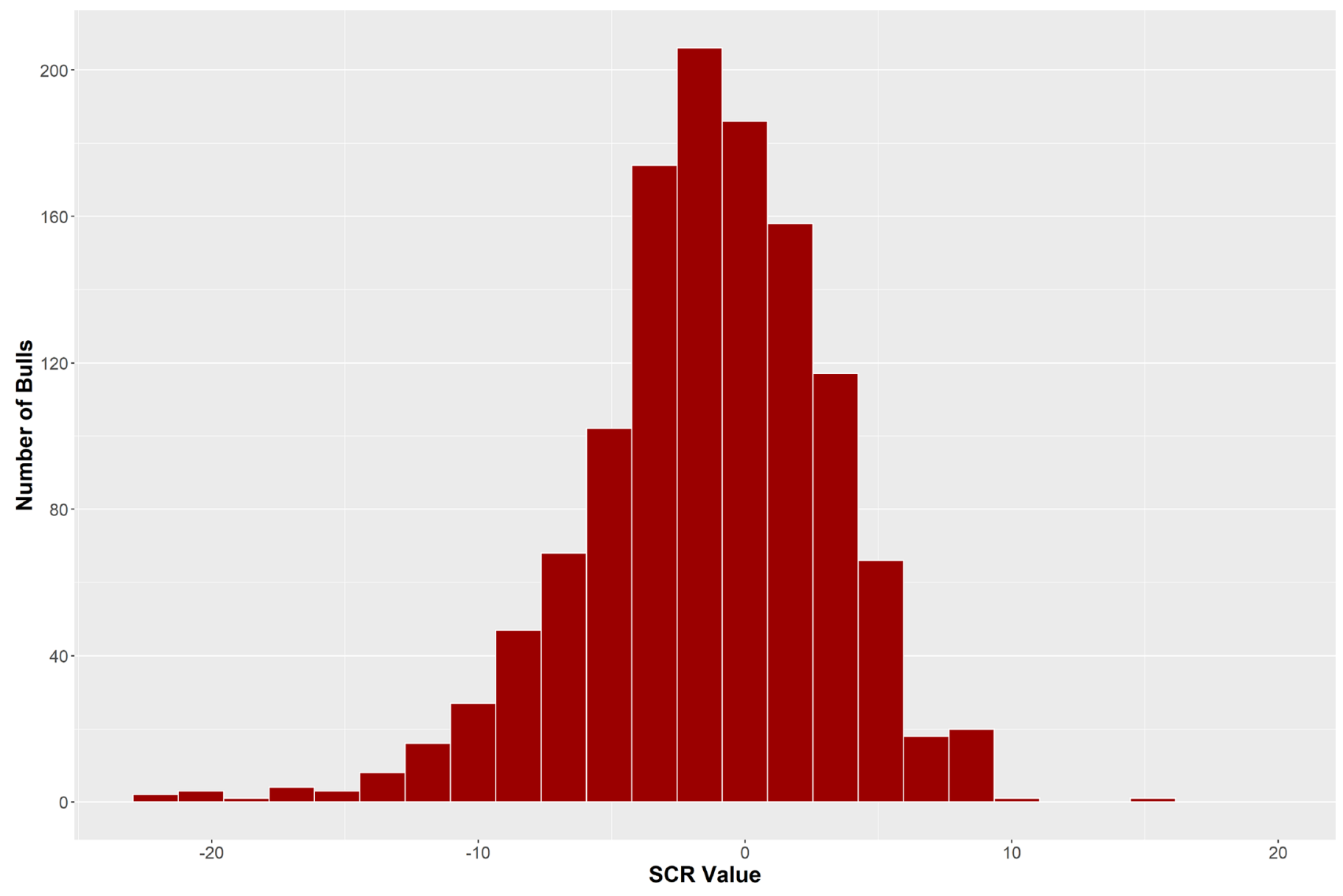

Figure 1. Distribution of sire conception rate (SCR) values for 1,228 Italian Brown Swiss bulls evaluated using 397,926 insemination records. 
so each analysis resulted in 100 estimates of predictive correlation (Figure 3). The estimates obtained in the training set were used to predict SCR values in the testing set. Predictive performance of the different sire conception rate models (models derived from the alternative cow pregnancy success analyses described above) was assessed using the Pearson product moment correlation between predicted SCR values and bull's $\mathrm{CR}$ in the testing population. The first model (base model) resulted in an average correlation of $29.9 \%$ between SCR and bull's CR, where in the second model the average correlation decreased to $28.2 \%$ with the addition of MY. When including AIcompany_year in the third model, the average correlation increased to $30 \%$, and in the fourth model, with all the previous variables plus Inbreeding mating $_{\text {, }}$, the average correlation was equal to $30 \%$.

\section{DISCUSSION}

Establishing a successful pregnancy in dairy cattle is a complex process, and there is strong evidence that not only the female fertility, but also the male fertility, plays an important role. However, bull fertility is often overlooked as a potential cause of reproductive inefficiency in dairy cattle. This seems to be contradictory considering that semen from one service sire bull is used to inseminate hundreds of cows, and thus, one subfertile bull would have a larger effect on the overall herd fertility than a single cow with fertility problems (Nani et al., 2019). Moreover, male fertility is conventionally estimated using only semen traits, but this analysis explains only part of the differences observed in fertility among bulls. Alternatively, dairy bull fertility can be directly evaluated using field records (e.g., confirmed

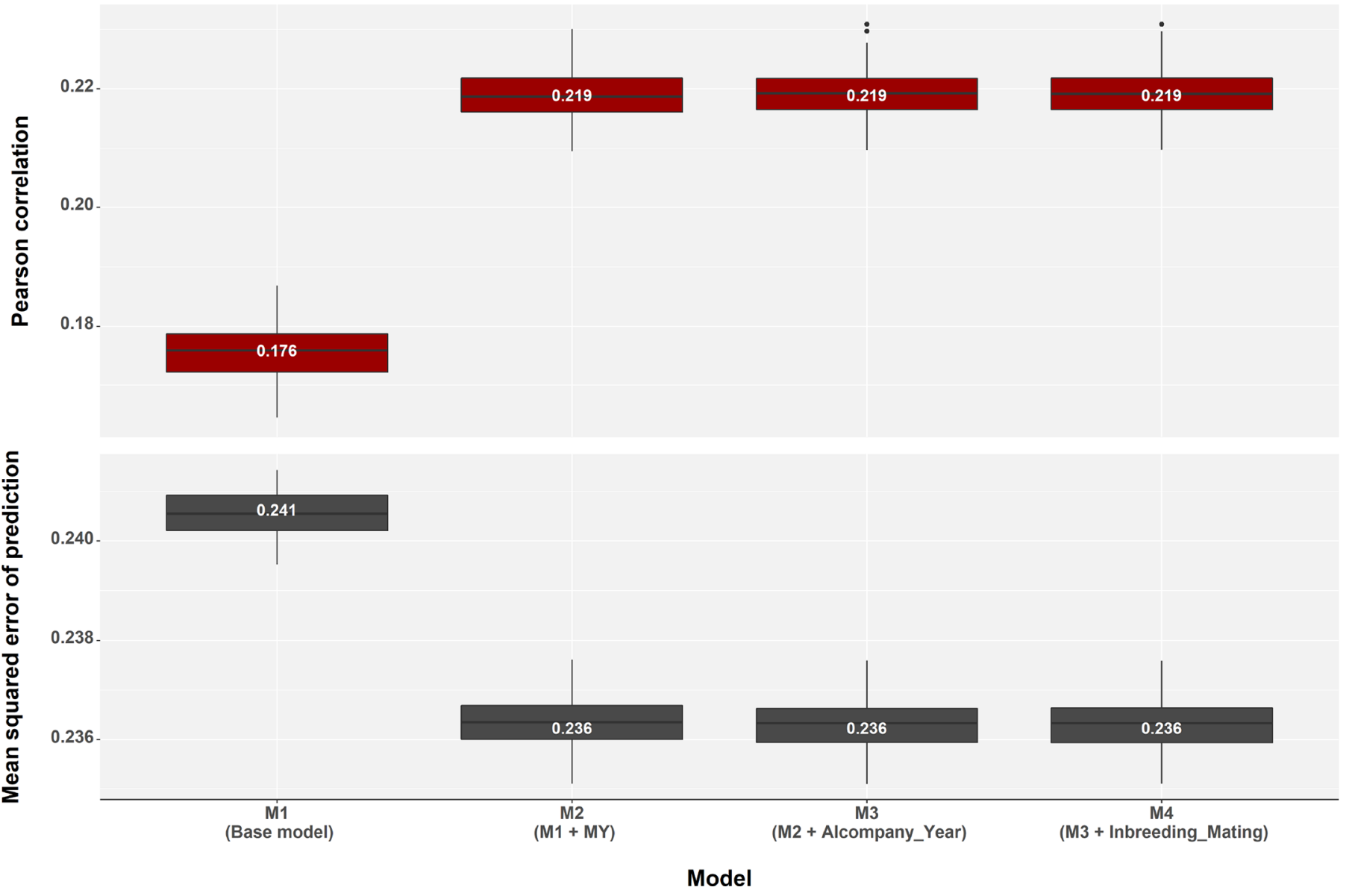

Figure 2. Predicting ability of 4 different models (M1-M4) for cow pregnancy success. Predictive correlations were calculated using 10-fold cross-validation with 10 replicates. Pearson correlation (top) and mean squared error of prediction (bottom) were evaluated for each model. The bottom and top of the box represent first and third quartiles, respectively; the horizontal line denotes the median; the whiskers correspond to $1.5 \times$ interquartile distance; and dark dots are outliers. MY = milk yield; AIcompany_year $=$ AI company within year; Inbreeding_mating $=$ inbreeding of the potential embryo. 
pregnancy records). As such, the present study was specially conducted to investigate bull fertility in the Italian Brown Swiss dairy cattle population using cow field records.

The statistical model for cow pregnancy success included factors related to both the bull under evaluation and the cow that receives the dose of semen. Among those variables, cow additive genetic effect explained the largest variance, $3.9 \%$ of the total variance. This value is higher than those reported by Tiezzi et al. (2013) when they evaluated nonreturn rate at $56 \mathrm{~d}$ after service (cow effect $=1.9 \%$ ) and calving per service (cow effect $=0.5 \%$ ) in Italian Brown Swiss cattle. The bull effect explained $1 \%$ of the total variance, very similar to what was reported by Tiezzi et al. (2013) for nonreturn rate at $56 \mathrm{~d}$ after service. Last, AI company, which was combined with year to account for potential changes that could occur in different years within the same AI company, explained the smallest proportion of total variance, only $0.2 \%$. In addition to that, the predictive performance of 4 different models for cow pregnancy success were evaluated using 10fold cross-validation. The first model, which included all the cow and bull-associated variables, except MY, AIcompany_year, and Inbreeding mating, $_{\text {, }}$ resulted in an average predictive correlation of $17.6 \%$. When MY was included in the model, the average predictive correlation increased to $21.9 \%$. In the third and fourth model, the sequential inclusion of variables AIcompany_year and Inbreeding mating , respectively, did not alter the predictive correlation of the model, which averaged $21.9 \%$ as well. These findings suggest that the prediction of pregnancy success is feasible, and MY is an important variable that should be included in the models.

The SCR model included only variables related to the bull under evaluation, as proposed by Kuhn et al. (2008). The SCR records followed a bell-shaped distribution but with long tails, denoting that most of the bulls have similar fertility but there are some important differences between the extremes of the population. In

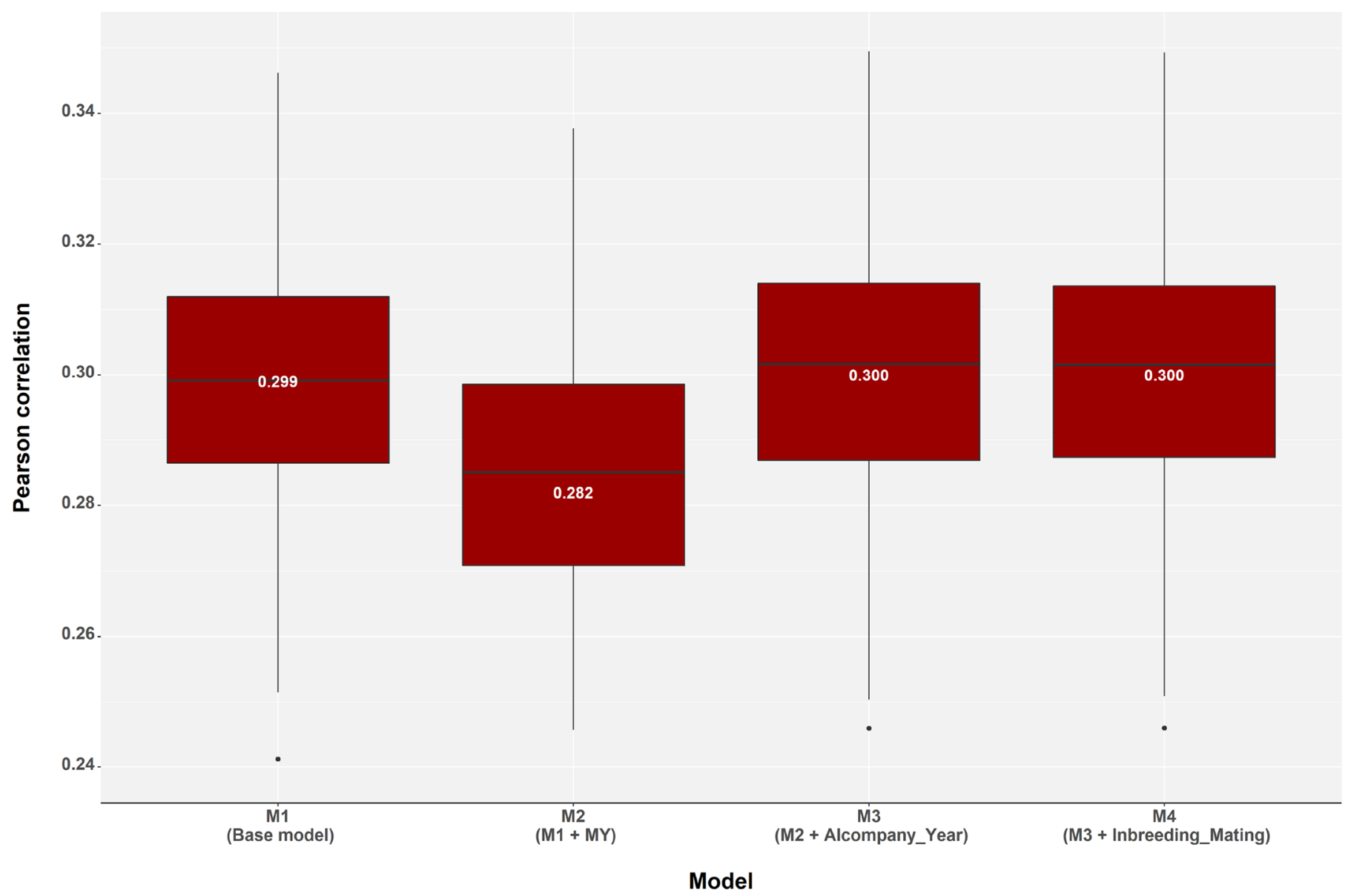

Figure 3. Boxplots showing the predictive performance of the 4 different models (M1-M4) based on the Pearson correlation of sire conception rate and bull's conception rate. MY = milk yield; AIcompany_year = AI company within year; Inbreeding_mating = inbreeding of the potential embryo. 
fact, there was more than $20 \% \mathrm{CR}$ difference between high-fertility and low-fertility bulls. This result is similar to what was observed in both US Holstein and US Jersey bulls, where there are about 10 to $15 \%$ differences in SCR values between high-fertility and lowfertility bulls (Peñagaricano et al., 2012; Rezende et al., 2018). Recently, McWhorter et al. (2020) evaluated the fertility of Angus sires bred to US Holstein cows, also reporting $10 \%$ CR difference between high-fertility and low-fertility sires. Interestingly, $20 \%$ of the variation in SCR was explained by additive genetic effects, and this result is similar to what was reported for US Holstein and US Jersey breeds (28 to 30\%; Abdollahi-Arpanahi et al., 2017; Rezende et al., 2019). Moreover, the assessment of model predictive ability for sire conception rate showed that SCR is a predictable trait, with an average correlation of $30 \%$. In addition to that, we also assessed the SCR correlation between 44 Brown Swiss bulls, which are in common between the United States and Italy, achieving a moderate correlation of $35 \%$, even when both evaluations are somewhat different.

One of the major challenges of the dairy industry worldwide is to improve overall herd fertility. For this, it is essential to have an accurate phenotype for bull fertility and turn it into an accessible evaluation, as it is already done worldwide for female fertility traits. It should be noted that national dairy bull fertility evaluations are implemented only in a few countries, including SCR in the United States and SFV in Australia (Carrick et al., 2000; Kuhn and Hutchison, 2008; Kuhn et al., 2008). Having a male fertility phenotype brings the opportunity to explore genetic factors that might explain the variability of bull fertility observed in the field. Recent studies have been successful in identifying candidate genomic regions, individual genes, biological processes, and molecular mechanisms underlying the fertility of dairy bulls using US SCR records (Han and Peñagaricano, 2016; Nicolini et al., 2018; Rezende et al., 2018; Pacheco et al., 2020). Moreover, several studies have reported promising results about predicting dairy bull fertility using genomic data (Abdollahi-Arpanahi et al., 2017; Nani et al., 2019; Rezende et al., 2019, 2020; Pacheco et al., 2020).

\section{CONCLUSIONS}

This study provides evidence that the assessment of Brown Swiss dairy bull fertility using cow field records is feasible. Our analyses using cross-validation techniques achieved predictive correlations equal to $22 \%$ and 30\% for cow pregnancy success and SCR, respectively. Interestingly, there is a notable variation in SCR between high-fertility and low-fertility Italian Brown Swiss bulls. This study represents the foundation for the development of novel tools that will allow dairy producers, breeders, and AI companies to make enhanced management and selection decisions on Brown Swiss male fertility. In addition, our findings suggest the opportunity to explore potential genetic factors that explain part of the differences in fertility among dairy sires.

\section{ACKNOWLEDGMENTS}

The authors have not stated any conflicts of interest.

\section{REFERENCES}

Abdollahi-Arpanahi, R., G. Morota, and F. Peñagaricano. 2017. Predicting bull fertility using genomic data and biological information. J. Dairy Sci. 100:9656-9666. https://doi.org/10.3168/jds 2017-13288.

Abdollahi-Arpanahi, R., F. Peñagaricano, H. Aliloo, H. Ghiasi, and J. I. Urioste. 2013. Comparison of Poisson, probit and linear models for genetic analysis of number of inseminations to conception and success at first insemination in Iranian Holstein cows. Livest. Sci. 153:20-26. https://doi.org/10.1016/j.livsci.2013.01.009.

Berry, D. P., R. D. Evans, and S. Mc Parland. 2011. Evaluation of bull fertility in dairy and beef cattle using cow field data. Theriogenology 75:172-181. https://doi.org/10.1016/j.theriogenology.2010.08 .002 .

Carrick, M., M. E. Goddard, and P. J. Bowman. 2000. Evaluation of bull fertility using field data (corrected NRR and CCR). Pilot system for routine collation of non return data for bulls. Pages 9-24 in Predicting and Monitoring the Fertility of Artificial Insemination Sires. The University of Queensland, Brisbane, Australia.

CDCB. 2020. December 2020 elite cow and heifer statistics. May 14 2020 ed. Council on Dairy Cattle Breeding. Accessed Jan. 6, 2021 https://queries.uscdcb.com/eval/summary/elitestat.cfm.

Cole, J. B., D. J. Null, and P. M. VanRaden. 2016. Phenotypic and genetic effects of recessive haplotypes on yield, longevity, and fertility. J. Dairy Sci. 99:7274-7288. https://doi.org/10.3168/jds.2015 $-10777$

DeJarnette, J. M., C. E. Marshall, R. W. Lenz, D. R. Monke, W. H. Ayars, and C. G. Sattler. 2004. Sustaining the fertility of artificially inseminated dairy cattle: The role of the artificial insemination industry. J. Dairy Sci. 87:E93-E104. https://doi.org/10.3168/ jds.S0022-0302(04)70065-X.

European Brown Swiss Federation. 2015. Why Brown Swiss? European Brown Swiss Federation. Accessed Jan. 6, 2021. https://www .brown-swiss.org/why-brown-swiss.

García-Ruiz, A., J. B. Cole, P. M. VanRaden, G. R. Wiggans, F. J. Ruiz-López, and C. P. Van Tassell. 2016. Changes in genetic selection differentials and generation intervals in US Holstein dairy cattle as a result of genomic selection. Proc. Natl. Acad. Sci. USA 113:E3995-E4004. https://doi.org/10.1073/pnas.1519061113.

Han, Y., and F. Peñagaricano. 2016. Unravelling the genomic architecture of bull fertility in Holstein cattle. BMC Genet. 17:143. https: //doi.org/10.1186/s12863-016-0454-6.

Immler, S. 2018. The sperm factor: Paternal impact beyond genes. Heredity 121:239-247. https://doi.org/10.1038/s41437-018-0111-0.

Inchaisri, C., R. Jorritsma, P. L. Vos, G. C. van der Weijden, and H. Hogeveen. 2010. Economic consequences of reproductive performance in dairy cattle. Theriogenology 74:835-846. https://doi .org/10.1016/j.theriogenology.2010.04.008.

Kastelic, J. P., and J. C. Thundathil. 2008. Breeding soundness evaluation and semen analysis for predicting bull fertility. Reprod. Domest. Anim. 43:368-373. https://doi.org/10.1111/j.1439-0531 2008.01186.x.

Kropp, J., F. Peñagaricano, S. M. Salih, and H. Khatib. 2014. Invited review: Genetic contributions underlying the development of pre- 
implantation bovine embryos. J. Dairy Sci. 97:1187-1201. https:// doi.org/10.3168/jds.2013-7244.

Kuhn, M. T., and J. L. Hutchison. 2008. Prediction of dairy bull fertility from field data: Use of multiple services and identification and utilization of factors affecting bull fertility. J. Dairy Sci. 91:24812492. https://doi.org/10.3168/jds.2007-0743.

Kuhn, M. T., J. L. Hutchison, and H. D. Norman. 2008. Modeling nuisance variables for prediction of service sire fertility. J. Dairy Sci. 91:2823-2835. https://doi.org/10.3168/jds.2007-0946.

McWhorter, T. M., J. L. Hutchison, H. D. Norman, J. B. Cole, G. C. Fok, D. A. L. Lourenco, and P. M. VanRaden. 2020. Investigating conception rate for beef service sires bred to dairy cows and heifers. J. Dairy Sci. 103:10374-10382. https://doi.org/10.3168/ jds. 2020-18399.

Misztal, I., S. Tsuruta, D. A. L. Lourenco, Y. Masuda, I. Aguilar, A. Legarra, and V. Vitezica. 2018. Manual for BLUPF90 family of programs. University of Georgia. Accessed Dec. 10, 2020. http:// nce.ads.uga.edu/wiki/doku.php?id=documentation.

Nani, J. P., F. M. Rezende, and F. Peñagaricano. 2019. Predicting male fertility in dairy cattle using markers with large effect and functional annotation data. BMC Genomics 20:258. https://doi .org/10.1186/s12864-019-5644-y.

Nicolini, P., R. Amorin, Y. Han, and F. Peñagaricano. 2018. Wholegenome scan reveals significant non-additive effects for sire conception rate in Holstein cattle. BMC Genet. 19:14. https://doi.org/10 .1186/s12863-018-0600-4.

Norman, H., L. Walton, and J. Dürr. 2018. Reproductive status of cows in dairy herd improvement programs and bred using artificial insemination. Council of Dairy Cattle Breeding. Accessed Jan. 9, 2021. https://queries.uscdcb.com/publish/dhi/current/reproall .html.

Ortega, M. S., J. G. N. Moraes, D. J. Patterson, M. F. Smith, S. K. Behura, S. Poock, and T. E. Spencer. 2018. Influences of sire conception rate on pregnancy establishment in dairy cattle. Biol. Reprod. 99:1244-1254. https://doi.org/10.1093/biolre/ioy141.

Pacheco, H. A., F. M. Rezende, and F. Peñagaricano. 2020. Gene mapping and genomic prediction of bull fertility using sex chromosome markers. J. Dairy Sci. 103:3304-3311. https://doi.org/10.3168/jds .2019-17767.
Peñagaricano, F., K. A. Weigel, and H. Khatib. 2012. Genome-wide association study identifies candidate markers for bull fertility in Holstein dairy cattle. Anim. Genet. 43(Suppl 1):65-71. https://doi .org/10.1111/j.1365-2052.2012.02350.x.

Rezende, F. M., G. O. Dietsch, and F. Peñagaricano. 2018. Genetic dissection of bull fertility in US Jersey dairy cattle. Anim. Genet. 49:393-402. https://doi.org/10.1111/age.12710.

Rezende, F. M., M. Haile-Mariam, J. E. Pryce, and F. Peñagaricano. 2020. Across-country genomic prediction of bull fertility in Jersey dairy cattle. J. Dairy Sci. 103:11618-11627. https://doi.org/10 .3168/jds.2020-18910.

Rezende, F. M., J. P. Nani, and F. Peñagaricano. 2019. Genomic prediction of bull fertility in US Jersey dairy cattle. J. Dairy Sci. 102:3230-3240. https://doi.org/10.3168/jds.2018-15810.

Soderquist, L., L. Janson, K. Larsson, and S. Einarsson. 1991. Sperm morphology and fertility in AI bulls. J. Vet. Med. 38:534-543. https://doi.org/10.1111/j.1439-0442.1991.tb01045.x.

Stahlhammar, E., L. Janson, and J. Philipsson. 1994. Genetic studies on fertility in AI bulls environmental and genetic effects on nonreturn rates of young bulls. Anim. Reprod. Sci. 34:193-207. https: //doi.org/10.1016/0378-4320(94)90016-7.

Tiezzi, F., C. Maltecca, M. Penasa, A. Cecchinato, and G. Bittante. 2013. Short communication: Genetic analysis of dairy bull fertility from field data of Brown Swiss cattle. J. Dairy Sci. 96:7325-7328. https://doi.org/10.3168/jds.2013-6885.

Walsh, S. W., E. J. Williams, and A. C. Evans. 2011. A review of the causes of poor fertility in high milk producing dairy cows. Anim. Reprod. Sci. 123:127-138. https://doi.org/10.1016/j.anireprosci .2010.12.001.

\section{ORCIDS}

Hendyel A. Pacheco @ $\odot$ https://orcid.org/0000-0001-9650-4657

Mara Battagin @ https://orcid.org/0000-0001-7309-6793

Attilio Rossoni ๑ https://orcid.org/0000-0001-5202-5785

Alessio Cecchinato 으 https://orcid.org/0000-0003-3518-720X

Francisco Peñagaricano ๑ https://orcid.org/0000-0001-6661-3991 